\section{CLINICAL - LECTURE}

\section{CASE O F I N F L U E N Z A :}

WITH

PERSISTENT HEADACHE AND JARRING SENSATION; FAILURE OF TONICS AND SIIIMULANTS ; SUCCESS OF BROMIDE OF POTASSIUM AND A STERNUTATORY.

By C. H A N D F I E L D J O N E, M.B., F.R.S., Physician to St. Mary's Hospital.

H. G., aged 29, millboard-maker, was admitted December 3Ist, I869. $\mathrm{He}$ had been ill nine weeks. He had at first a violent cold in the head, and much running from the nose, but not much cough. He had still some remains of this cold. He had had a great deal of retching; no actual vomiting. He complaired of pain in the head from the tem ples to the occiput; most pain in the left temple. $\mathrm{He}$ had a ringing noise in his left ear, and felt always as if there were "a jumping in the head which jarred him all over". The head was not tender now to tapping; some days it was very much so. He had had, and still had, a craving appetite; he wanted something to eat every two or three hours, and, if he did not get it, felt as if he would sink through the bed, and experienced a dull weary pain at the upper abdomen. $\mathrm{He}$ felt very low, and sweated profusely at night. He had much flatulence. Tongue moist. $\mathrm{He}$ had no pain after eating. The bowels were open daily. Pulse 81, of fair apparent force; temperature 37.3 deg. (99.1 deg.) The urine was pale, not albuminous, of specific gravity 1012. He had no paralysis. He denied having had syphilis and gonorrhœea. He had been treated by a medical man, who told him he had a water-congestion on the brain, blistered his neck and occiput, and put a leech behind each ear, which bled freely. He was put on ordinary diet, with four ounces of port wine; and was ordered to take the following draught three times a day.

R Ammoniæ carbonatis gr. iv ; spirit. æther. sulph. comp. 3ss ; tincturæ cinchonæ $3_{s s}$; decocti cinchonæ $\bar{j} \mathrm{j}$. M.

Jan. 3rd. He had less sweating. His head was not in any pain as long as he kept it warm; but the ringing and throbbing continued The forehead was cool. He did not sleep soundly. He still felt very low. Pulse good and steady, 72. He was ordered to take the following three times a day.

R Strychniæ gr. I-20; acidi nitrici mij; spirit. æther. chlor. $m x$ aquæ $\xi j$.

Jan. 5 th. The jarring sensation, extending all over him from the head, still continued; and the ringing in the left ear. $\mathrm{He}$ had been very deaf in that ear for three or four years. He could not hear the watch tick when it touched the left ear, but could hear it with the right at six inches. There was a little discharge from both ears. His appetite was still very craving. Wine relieved the gnawing and craving sensation. He was ordered half a grain of extract of Indian hemp and half a grain of opium three times a day. On the 12 th, the head was tender to tapping. There was no improvement; and the remedies were changed for one-sixteenth of a grain of bichloride of mercury, eight grains of iodide of potassium, and ten minims of spirit of chloric ether, three times daily, in an ounce of water. After some days, Indian hemp, in fifteen-minim doses of the tincture, three times a day, was given also; but no ground was gained till, on the 2 Ist, I prescribed one-third of a grain of nitrate of silver and one grain of extract of poppies three times a day. The report on the $29^{\text {th }}$ was, that his head was a wonderful deal better; but, when it was dependent, he had a sensation of a rush of blood to it Our aural surgeon, Mr. Allen, informed us that the left ear was in a state of chronic catarrh, the membrana tympani drawn in by adhesions in the tympanic cavity, and the Eustachian tube obstructed on the left side. The tinnitus was consequent on these alterations.

Feb. 2nd. His head was nearly as bad again as ever, since he got an attack of shivering. on January 3oth, and some diarrhœea. I ordered him to use common snuff five times a day, and to take two grains of quinine three times daily. The pain in the head was very bad the following night, and his face was much flushed. He could not sneeze, however much snuff he took. I then substituted for common snuff the following sternutatory, which is recommended by Dr. Laycock : R Pulv. hellebori albi gr. 40, pulv. cinchon. ad $\xi$ ss; and I gave thirty grains of bromide of potassium and an ounce of camphor mixture every three hours. On the 5 th, his head was much relieved; the powder made him sneeze effectually, and some blood was expelled. On the 9 th, ringing in the ear was gradually dying away. The headache was much less; what pain there was, was frontal. His head had felt different altogether since he had the bromide. Mr. Allen reported that he could inflate the tympanum better. The hearing-distance was three inches for a loud-ticking watch.

He was made an out-patient soon afterwards, and was last seen on the 15 th, when he reported that he was almost quite free from headache. He attributed much benefit to the hellebore snuff. The bromide had been continued in twenty-grain doses three times a day.

REMARKS. - The following points seem pretty clear in this case: 1. That the patient had been affected with tympanitis of the left ear for some years prior to the commencement of the headache, so that the latter can hardly be referred to the aural disease; 2 . That he had undergone a severe attack of influenzal catarrh, which, in all probability, gave rise to the headache and the jarring sensation felt all over him; 3. That the craving appetite, sinking sensations at the epigas trium, and profuse nocturnal sweatings, were other results of the influenzal attack, and indications of its prostrating action on the nervous system; 4. That the headache was not, as I was inclined to regard it at one time, of syphilitic origin.

There remain for our consideration-I. The nature of the head-pain and jarring sensation which attended it;2. The action of the remedies which proved beneficial.

As to the first, we shall hardly err if we attribute the symptoms to the direct toxic effect of the influenzal miasm on the encephalon. It is surely rational to think that a poison received into the system may directly affect the nutrition of the nerve-cells, without altering in a notable manner the blood-supply of the great centres. When a man is the subject of alcoholic coma, we do not suppose him to have congestion of the brain, or, at any rate, that this is the cause of his stupor but we simply affirm that he is intoxicated, or, in plain English, poisoned. In many other similar cases, we take generally the same view but, when we come to more obscure instances of poisoning by aërial and invisible miasms, there seems to be a great tendency to assume congestion or effusion as the chief causes of cerebral symptoms, and to leave out of count the direct operation of the morbific agent on nervous tissue. I cannot help thinking that this error often leads to bad practice.

Too many are inclined, I fancy, to look upon influenza as essentially a bronchial catarrh; but I quite agree with Graves and Blakiston that its cause acts in a special manner on the nervous system, and that it is no mere inflammation. The peculiar prostration, the headache and other nervous symptoms, which are not unfrequent, differentiate it markedly; besides the suddenness of invasion, which is often very remarkable. I will narrate a case briefly to you which illustrates these points well. T. P., aged 32, had been in hospital three weeks under my care for epididymitis, and was nearly well, when he was taken one morning, about I0.30, with severe headache, prostration, and fever. His pulse was very weak, I35, and his temperature 106.5, the same afternoon. There was some deficiency of breathing at the right posterior base, but no marked dulness or crepitation. The lungs continued free; the temperature and pulse soon declined to a lower, though still febrile rate; but his brain remained seriously enfeebled for more than a fortnight after his seizure, and he convalesced very slowly. Giddiness and prostration of mental activity were the most remarkable phenomena. Ten days after his seizure, he staggered and fell down when he got out of bed; and, a week later, he was so torpid and silent that I had some difficulty in getting him to answer questions. His pulse and temperature had, however, become natural, except that the former was very feeble. Here it was manifest that the stress of the disease fell altogether on the encephalon, and that the lungs were very slightly affected. In our first case, it was much the same, though there seems to have been a greater amount of catarrh.

Another instance worth mentioning is that of a middle-aged lady who had very great prostration of brain-power, so that she could scarcely attend to her household matters. Strychnia did her great good. Her husband at the same time had severe catarrh, coughed violently in the early morning, and sweated so copiously at night that he had to change his night-shirt.

It is hardly an hypothesis to say, that in the first of these cases the hemispheres, and in the second the vaso-motor nerves, were almost solely affected. The lady remarked to me, that she supposed she had "suppressed catarrh"

The peculiar jarring sensation throughout his body which our patient experienced can only be regarded, I believe, as a modification of cerebral derangement, dependent perhaps on special implication of the sensory nerve nuclei. That, under certain circumstances, the normally in sensitive hemispheres may become the seat of pain, I can hardly doubt. A man, aged 70, consulted me once, complaining of " a soreness of the 
brain"; any motion or coughing jarred and hurt his head, or rather its contents. His head, however, was not tender to tapping. He had no rheumatism; no syphilis; no paralysis. His intellect was clear; but he had sensations of things crawling about the lower part of his forehead. The age of this patient would make one suspect calcification of the cerebral arteries; and this might occasion the symptoms complained of. However this may be, there can be little question that, owing to some defect in nutrition, the cerebral nerve-tissue became intolerant of slight commotions, which ordinarily it could have endured very well.

But, to return to our patient: I do not think the peculiar dysæsthesia of which he complained-the jarring sensation-was of any special significance. No doubt, some minute modification of molecular arrangement corresponds to each of the manifold dysæsthesia which such sufferers experience; but these are far beyond our ken, and it is not of any vital importance to the practitioner to be acquainted with them. The subjective phenomena (the same is true of the objective) are no sure guide to the quality of the disorder; and this is what especially concerns us. You will never treat derangements of the nervous system successfully, if you suppose that all phenomena having the same outward appearance are really alike. Cases of delirium, of spasm, of neuralgia, differ very greatly, though, as far as phenomena go, they are identical. In the case of H. G., I was led into error at first by the history and by the evident signs of prostration of nerve-power. These led me to give tonics and stimulants, which availed nothing for the relief of his head. When, however, I administered an unexciting calmative, aided by a counterirritant (for such I consider the sternutatory), improvement ensued rapidly. You may perhaps think that such a remedy ought, on rational grounds, to have been employed at once; and that stimulants were inappropriate to the symptom pain. A little experience, however, will show you that, in a multitude of instances in which debility constitutes a prominent feature, stimulants are most efficacious sedatives. Two or three glasses of port wine will remove, for the time, neuralgia in some cases. All neuralgic pain, however, is not to be thus dealt with; and you may need, to allay it, remedies which are very much the reverse of stimulants, such as hydrocyanic acid, bromide of potassium, aconite, and moist warmth. When I find such means as these successful, I think the condition is thereby at once differentiated from that in which our ordinary tonics avail; just as much as two different saline solutions are distinguished by chemical tests.

As I have above said, I cannot tell you in what the essential difference consists; but $I$ find it of value to keep in my own mind the two conditions separate, and to denote them by some such terms as neuralgia and hyperæesthesia. It may aid us in forming more definite conceptions of these two states, if we call to mind their analogues among motor disorders, such as choreal paralysis and jactitation, which, though extremely unlike, undoubtedly originate in the same morbid process, and are, so to speak, truly homogeneous. It is a fact, that all causes which impair strength are very prone to generate hyperexcitability, which may show itself in the sensory, or motor, or intellectual departments.

Lastly, as to the sternutatory. This must be regarded as a form of counterirritation; having this advantage, however, that it is capable of repeated application within a short time; and that it provokes repeated diversions of blood, with mucous exudation. The formula which I employed is that recommended by Dr. Laycock; and you see that it was very positively more efficacious than common snuff. Its good effect in our patient depended, I think, on its producing reflex stimulation of the vaso-motor nerves of the cerebral arteries, and lessening the blood-flow, which was probably excessive for the weakened tissue. I emphasise the word weakened; for I hold it well ascertained, that an organ whose vitality is vigorous can bear and employ beneficially a much larger supply of blood than one which is in an opposite state. The nerves of the Schneiderian membrane are perhaps better fitted than any to exert this constringing influence. At the same time that the sensory nerves of this membrane are excited, its vaso-motor are, in all probability, relaxed; so that the vessels become suddenly congested, and modified blood-fluid and corpuscles escape. This seems to be the general rule in all localities, that tissue-excitement determines vasal relaxation. Fatal cases of tetanus and chorea afford marked examples; the vessels of the cord or other nervous centres being engorged, and rupture and extravasation having ensued in some places. To an hyperexcitable organ, an undue amount of blood-flow is certainly injurious; so that it is good practice to try to calm tissue-excitement while we constringe vessels.

I do not know that I can altogether explain the mode of action of counterirritants; but their utility, in spite of recent scepticism, I do not doubt; and I strongly advise you not to doubt.

To conclude, let me counsel you to familiarise your minds with such common things as the management of headache in its various forms. Many of you may never perform lithotomy, nor perhaps amputate; yet students crowd to gaze at the great operations, of which they can see next to nothing, and which they are little likely ever to perform; while they can hardly be brought to give a thought to the treatment of a malady which they may have to deal with any day of their lives.

\section{CASES AND COMMENTARIES.}

By HYDE SALTER, M.D.; F.R.S.,

Fellow of the Royal College of Physicians; Physician to Charing Cross Hospital; Lecturer on Medicine at the Charing Cross Hospital Medical School.

No. I.-Case of Double Aortic Disease.-History of Case and peculiarities of Physical Signs. - Diastolic Impulse.-Relations of Diastolic Murmurs to Diastole.

HENRY BenNeTt, aged 38 , a tall, spare, sallow man, with thin, lank, black hair, by occupation an engine-fitter, temperate, married, with four children, all healthy, was admitted into Charing Cross Hospital on December 28th, 1869. He has for years suffered from an undue beating of the heart, but not enough to interfere with his work; a twelvemonth ago this palpitation became more violent; at that time, he had an attack of bronchitis, from the heats and chills to which he was exposed in his occupation, and it was on recovering from the bronchitis that he noticed that the palpitation had increased. Eight weeks ago he experienced a further and sudden increase of it, without any bronchitis, or any assignable cause; and now to the palpitation was added dyspnœa-he was unable to walk quickly, or work at his employment, and on lying down at night his breath was very short, and his heart seemed beating in his throat, so that he was obliged to jump up in bed again; from that time, too, he has, almost every night, suffered from orthopnœe, being aroused from his sleep by a sense of suffocation, starting up and labouring for his breath with the utmost violence ; especially does this occur if he lies on his left side. He has, too, what he never had before, a sense of uneasiness in the epigastrium accompanying these attacks of palpitation and breathlessness. He has never had rheumatic fever, or rheumatism in any form.

Physical Examination.-On stripping the man, two things are at once seen ; first, a strong pulsation of all the arteries, at the root of the neck, arms, etc.; and, secondly, an undue visibleness of the heart's movements over the whole of the front of the chest, especially in the intercostal spaces of the left side, and the scrobiculus. The apex is seen strongly beating between the sixth and seventh rib, at a distance of four inches in a vertical line dropped from the left nipple, and seven inches and a half from the base of the heart. A fluctuous brush of wave-like movement, passing from the region of the apex to the left at each pulsation, is very striking and conspicuous in the fifth and sixth intercostal spaces. On listening at the base, a double murmur is heard, the two running into one another-the first soft and faint, the second loud, rough, and terminating abruptly. On checking these with the pulse, the first is found to be systolic, the second diastolic. There is, therefore, double aortic mischief, constrictive and regurgitant. It would be diffcult, perhaps, to say at which margin of the sternum the basic murmur is the loudest; I think the left; but it is decidedly of deeper and softer tone at the right, flatter and harsher at the left, and more conspicuously abrupt in its termination. At the apex, a loud single murmur is heard, accompanying the stroke of a very strong impulse, so strong as to raise the stethoscope with great force against the ear. This impulse has all the characters of a heaving thumping systole, but on checking it by the pulse, I found, to my surprise, that it was diastolic, while at the systole there was no perceptible impulse whatever. About the diastolic period of this violent impulse there could be no doubt. I checked it in every way. On applying the fingers of one hand to the apex, and of the other to the wrist, the alternation of the heart's stroke and that of the pulse was very clear and striking; and on applying the stethoscope to the apex, and allowing its free end to move freely as a sphygmoscope, and comparing its movements with those of the visible pulsations of the radial artery, their alternation was equally conspicuous. I do not know that I have ever felt an impulse of greater strength, more thumping character, and wider distribution; and yet with this impulse the systole has nothing to do. At the period of the systole there is no trace of impulse, and hardly a trace of sound; what little sound is perceptible appears to me to be rather of the nature of a very soft and almost inaudible systolic murmur than having any of the character of a natural first sound. It is, however, so faint and so masked by the loud diastolic nurmur, that it is difficult to say anything as to its character. Nothing could be more misleading as to the heart's rhythm than such a diastolic impulse as this; not only its extraordinary strength, but its singleness, gave an impression of its systolic character that was almost irresistible; 